\title{
Regionalization and Trend Analysis of Seasonal Precipitation (1970 - 2020) using Hierarchical Clustering and Wavelet Transform Approach in the Mahi River Basin, India
}

\section{Aditya Sharma}

Central University of Rajasthan

Devesh Sharma ( $\nabla$ deveshsharma@curaj.ac.in )

Central University of Rajasthan

Shyam Sunder MS

Central University of Rajasthan

\section{Research Article}

Keywords: Hierarchical clustering, periodicity, seasonal rainfall, trend analysis, wavelet transform

Posted Date: August 26th, 2021

DOl: https://doi.org/10.21203/rs.3.rs-801500/v1

License: (c) (i) This work is licensed under a Creative Commons Attribution 4.0 International License.

Read Full License 
1 Regionalization and Trend Analysis of Seasonal Precipitation (1970 - 2020) using

2 Hierarchical Clustering and Wavelet Transform Approach in the Mahi River Basin, India

3

4

5

6

7 Aditya Sharma

8 Department of Atmospheric Science

9 School of Earth Science

10
Central University of Rajasthan

NH-8, Bandarsindri, Kishangarh-305817

Ajmer, India

Email: adityacuraj@gmail.com

*Devesh Sharma (Corresponding Author)

Department of Atmospheric Science

School of Earth Sciences

Central University of Rajasthan

NH-8, Bandarsindri, Kishangarh-305817

Ajmer, India

Email:deveshsharma@curaj.ac.in

Shyam Sunder MS

Department of Atmospheric Science

School of Earth Science

Central University of Rajasthan

NH-8, Bandarsindri, Kishangarh-305817

Ajmer, India

Email: murushyam@gmail.com 
Regionalization and Trend Analysis of Seasonal Precipitation (1970 - 2020) using Hierarchical Clustering and Wavelet Transform Approach in the Mahi River Basin, India

(1)

\section{Abstract}

Understanding the trend in seasonal precipitation in the context of climate change is crucial for the maintenance of regional water resources management. The present study examines the seasonal precipitation trend in the Mahi River basin, India by using the wavelet transform and clustering method. Very limited studies have been carried out over the basin using this approach. Daily gridded rainfall data $\left(0.25^{\circ} \times 0.25^{\circ}\right.$ spatial resolution) for 51 grids from 1970 to 2020 has been taken from India Meteorological Department (IMD) and the time series trend was tested by Mann-Kendall. The monthly, seasonal, and annual statistic has been analyzed for 51 years. We have also plotted the relationship of precipitation trend-elevation. After that, homogeneous precipitation regions are delineated with hierarchical clustering analysis. Results reveal that seasonal precipitation over the basin clusters into 4 subregions for monsoon (JJAS1 to JJAS4) and 3 subregions for winter, pre-monsoon, and post-monsoon seasons. After the regionalization of the subregions, the periodicity and the inter-seasonal relationship were analyzed using continuous wavelet transform (CWT). Findings revealed that the crosscorrelation between pre-monsoon and monsoon seasons highly affect significantly in past over the basin. Further, the regional geography-altitude and moisture convergence perform a major role in the variability of seasonal precipitation. The output of the current study would be utilized in a better understanding of precipitation forecast, watershed, and agricultural planning which may give a better climate change indication at a regional-basin level. We also suggest future needs to more focus on the understanding of elevation-dependent wetting in hilly regions using a different type of datasets.

Keywords: Hierarchical clustering; periodicity; seasonal rainfall; trend analysis; wavelet transform 


\section{Introduction}

The impact of changing climate on rainfall as well as on hydrology is a serious issue for various sectors-society at large in today's world. According to Intergovernmental Panel on Climate Change (IPCC), the change in mean variability of climate causes a change in property, which persists for a prolonged phase or decades (Masson-Delmotte 2018; Sharma et al. 2018; van der Wiel and Bintanja 2021). Moreover, due to this, the Himalayan glaciers are disappearing at a very faster rate, which is affecting the flow of rivers and the percolation of water (Jeelani et al. 2012; Hock et al. 2019). Globally, rivers are showing considerable changes in annual runoff alongside a decline in snowfall and an increase in glacier melt, causing a water deficiency in the long run (Oppenheimer et al. 2019). Also, Tabari 2020 stated almost all areas are expected to experience the harmful impact of changing climate on water environment and their ecosystems. This will affect global water resources as well as the water scarcity for the domestic and agricultural sector, which are further projected to experience an increase in the threat of droughts due to a reduction in precipitation rate (Hoegh-Guldberg et al. 2018; Boretti \& Rosa 2019).

In the area of hydrology, meteorology, and climate, precipitation is the most important variable used for many analyses. In India, to evaluate the influence of climate change on rainfall patterns and their irregularity was performed by many researchers (Döll et al. 2015; Mar et al. 2018). The climatic situation of India varies from one part or region to another. There is a great alteration in rainfall amounts at different locations (Praveen et al. 2020). During the last decades, the various parameters or character of the river basin are changing their properties due to climate change ( $\mathrm{Lv}$ et al. 2019). It is important to note that, in India, the annual rainfall is mostly maximum in ISM seasons (JJAS) and fluctuates spatially and temporally which causes the risk of disaster events at a broad scale. Hence, through past rainfall trend investigation, we can forecast precipitation and manage water resources problems easily (Feng et al. 2016). Loucks \& van Beek, 2017 also pointed that, regional site-specific rainfall trends improve in managing and distributing the water resources at a large scale. However, at the Indian level, some studies have been reported unclear and fluctuated rainfall trends (rise or fall) in the monsoon period (Sinha et al. 2015; Praveen et al. 2020).

On the other hand in hydro-meteorological studies, the determination of variables trend (rainfall and streamflow) gains the greatest importance. Globally, many studies have been conducted on 
the seasonal trend-analysis of precipitation, which helps in the planning and implementation of strategies in various sectors (Panda and Sahu 2019; Srivastava et al. 2021). Worldwide and in India, many research used different trend analysis methods for annual and seasonal rainfall at basin scale i.e. Hilbert-Huang transform (Reddy \& Adarsh 2016), discrete wavelet transform (Palizdan et al. 20217), Mann-Kendall test (Zamani et al. 2018), machine learning like ANNMLP (Amato et al. 2020; Praveen et al. 2020), innovative trend analysis (Wang et al. 2020) and many more. Out of several methods, the Mann-Kendall (MK) test is broadly used for the significance test in trend-analysis in several studies due to its monotonic (either rising or falling trend) characteristics (Alemu \& Dioha 2020). Moreover, other studies have observed major variations in the pattern and distribution of rainfall (Ghaedi and Shojaian 2020; Huang et al. 2021). Rai and Dimri 2020 noticed the sharp increase in inter-annual variability of rainfall and the high risk of rainfall incidents during the summer monsoon in India. Similarly, Kumar et al., 2010, have noted a large gap time deviation in rainfall pattern over 30 sub-division of India, where $1 / 2$ of the part indicates a rise in yearly rainfall. Therefore under changed climatic situations, the knowledge of hydrological responses over river basins would help to improve potential water scarcity problems associated with disaster events.

For regionalization of hydro-meteorological components, researchers used several approaches like principal-component assessment (PCA) (Cerón et al. 2020), hierarchical clustering assessment (HCA) (Zhu et al. 2020), empirical orthogonal-function (EOF) (Hermida et al. 2015), and simple correlation testing ( $\mathrm{Hu}$ et al. 2019). Out of all these methods, for cluster analysis, HCA is the most suitable method to identify meteorological homogeneous areas in the regions by grouping historical rain gauges datasets and points (Hu et al. 2019; Alam \& Paul 2020). Recently, Machiwal et al. 2019 investigated comparative analyses to find out the homogeneous rainfall gauge positions using a clustering algorithm. The potential effects due to climatic change may alter the pattern of precipitation and variability (Samra 2004). In India, some western states i.e. Rajasthan, Gujarat, and Madhya Pradesh have a solid link of seasonal rivers. Drought and dryness are common hazards in these regions because, they received more rain in ISM, and less in other seasons, which cause extensive severe water scarcity. Therefore, an investigation of long-term seasonal rainfall trends over various river basins of the western part of India is crucial especially for systematic planning of watershed hydrology. 
Furthermore, the determination of trends using efficient tools gains utmost importance like for time-series analysis using wavelet transform (WT). As per Hu et al. 2019, it is a very effective tool for the identification and differentiation of temporal periodicity of rainfall. Hence, WT has gained more importance in the temporal analysis of hydro-climatic datasets. This wavelet technique uses in many applications like using meteorological data with MK test (Ruwangika et al. 2020), drought periodicity by Yerdelen et al. 2021, and seasonal periodicity identification for detailed distribution of sequential dynamics of rainfall. Hence for periodicity identification and characterization, WT is one of the better methods nowadays and it gives a time-frequency understanding of domain data (Hochman et al. 2019; Chinchorkar 2019; Gupta \& Chavan 2021). However, to best our knowledge, no attempts have been made to investigate periodicities of inter-seasonal rainfall trends using WT in the western region (Mahi River basin) of India.

The climate of Mahi River basin is varied from semi-arid to humid, which is mainly influenced by two monsoon seasons i.e. winter and summer, and which affect the rainfall distribution pattern temporally and spatially over the region (MoWR 2014). Therefore, the specific objectives of this study include (1) regionalization of seasonal precipitation using HCA and (2) to determine dominant and significant periodicities in an inter-seasonal relationship using the wavelet transform method over the Mahi River basin. The overall study is organized as follows: section 2 described the picture of the study area. The datasets and methodology are highlighted in section 3, including wavelet transform. section 4 described the detail of the results and discussions. The main findings/conclusions are summarized in section 5. The results of this study will be of significance in providing a reference for monsoon prediction and water resource allocation in the western part (Mahi River basin) of India.

\section{Study Area}

The Mahi River, one of the main West flowing inter-state river of India, which originates from the Madhya Pradesh (tilt toward northern of the Vindhya Range), at an elevation of $500 \mathrm{~m}$ amsl. The basin positioned between $72^{\circ} 21^{\prime} \mathrm{E}$ to $75^{\circ} 19^{\prime} \mathrm{E}$ and $21^{\circ} 46^{\prime} \mathrm{N}$ to $24^{\circ} 30^{\prime} \mathrm{N}$ (Figure 1). The length of the river is $500 \mathrm{~km}$ and with a projected drainage area of about $34,842 \mathrm{~km}^{2}$, which is nearly $1 \%$ of the total terrestrial area of India (Maurya et al. 2021). On the north-west, it is bordered by the Aravalli hills and on the east, it is surrounded by the ridge that divides it from the Chambal basin. The Mahi basin cover three states i.e. Rajasthan having an area of 15,996 $\mathrm{km}^{2}(41.73 \%), 15,474 \mathrm{~km}^{2}$ (40.36\%) in Gujarat, and 6,866 km² (17.91\%) in Madhya Pradesh 
(MoWR 2014). The mean annual precipitation around the basin is $889 \mathrm{~mm}$, and out of which the outmost of the rainfall (97\% of total) received during the 4 monsoon months (June to September) (Pawar and Hire 2018). There are various water resource sites/dams alongside the reach that hindrance and control the river flow of the stream. Over the Mahi basin, two large dams are there i.e. Mahi Bajaj Sagar in Rajasthan and the Kadana Dam in Gujarat.

Figure 1: The geographical location map and IMD gridded points over the Mahi River basin, India

\section{Data used and methodology}

In this section, the data used and the overall methodology for the study are presented. Several descriptive statistics have been computed for the analysis of seasonal rainfall like, mean, SD, Coefficient of Variation (CV), and 5-year moving average. Furthermore, MK trend test was used to detect the trend of rainfall. The data analysis and HCA were performed for 4 seasons (JJAS) of rainfall by using XLSTAT, SPSS v 17.0, and an excel spreadsheet. Further, we have also analyzed the periodicities in seasonal rainfall using the wavelet transform in the $\mathrm{R}$ 4.0.2 studio. The overall methodology adopted for this study is shown in Figure 2. The detail about the methods used in this study is discussed in section 3.

Figure 2: Methodological framework used for the study

\subsection{Data}

The high-resolution daily gridded $\left(0.25^{\circ} \times 0.25^{\circ}\right)$ rainfall dataset of all over India region during 1970 to 2020 was obtained from the IMD, Pune (http://www.imdpu ne.gov.in/) (Srivastava et al. 2009; Pradhan et al. 2019). From this dataset, the daily time series for the 51 grid points over the basin have been extracted. The spatial location of these 51 grid points is shown in Figure 1 and their attributes in Table 1.

\section{Table 1: Grid locations and mean rainfall $(\mathrm{mm})$ over a study area}

Further, we have converted daily time series data of rainfall for each grid points into monthly and seasonal value using a pivot table in excel spreadsheet to detect rainfall behavior and their changing features in the trend. The distribution of meteorological seasons as per IMD is 
presented in Table 2. After that, the converted data were processed and analyzed for statistical calculation. For mapping and data analyzing, Arc GIS 10.3 and different packages under R 4.0.2 studio have been used.

Table 2: Distribution of meteorological seasons over India

Source:- Moni et al., 2020

\subsection{Mann-Kendall test}

Based on IMD seasonal precipitation data, the statistical trend analysis for all four seasons over the Mahi River basin was conducted using the R studio and ProUCL 5.1 software. For time series trend analysis of these seasonal data, we have used the MK significance test. Globally, many studies (Nisansala et al. 2020; Praveen et al. 2020) have used the MK test for using different datasets. If the data is taken from bulk with unbiased realizations and is allocated identically, then it will be denoted by $\mathrm{H}_{0}$ i.e. null hypothesis. If the data supports a monotonic trend, then it will be an alternative hypothesis, $\mathrm{H}_{\mathrm{a}}$. The Mann-Kendall test is achieved by using the following Equations 1-4.

$$
\mathrm{S}=\sum_{\mathrm{k}=1}^{\mathrm{n}-1} \sum_{\mathrm{j}=\mathrm{k}+1}^{\mathrm{n}} \operatorname{sgn}\left(\mathrm{x}_{\mathrm{j}}-\mathrm{x}_{\mathrm{k}}\right)
$$

with, Sgn $=\left\{\begin{array}{c}1 \text { if } x>0 \\ 0 \text { if } x=0 \\ -1 \text { if } x<0\end{array}\right.$

Mean of $S, E[S]=0$

$$
\text { Variance }\left(\sigma^{2}\right)=\left\{\mathrm{n}(\mathrm{n}-1)(2 \mathrm{n}+5)-\sum_{j=1}^{p} t\left(\mathrm{t}_{\mathrm{j}}-1\right)\left(2 \mathrm{t}_{\mathrm{j}+5}\right)\right\} / 18
$$

where $\mathrm{p}=$ No. of tied groups in the information $t_{j}=$ No. of data points in the $j^{\text {th }}$ tied group.

Kendall's $\tau=\mathrm{S} / \mathrm{D}$

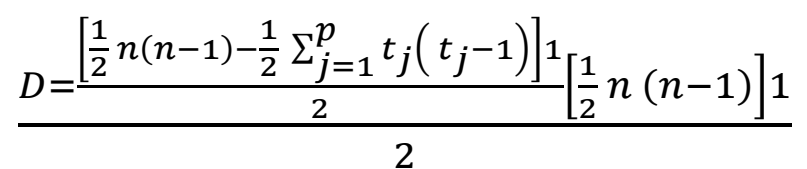


232 For calculation of test statistics (Z), the value of $\mathrm{S}$ and $\operatorname{Var}(\mathrm{S})$ are used:

$$
Z=\left\{\begin{array}{c}
\frac{s-1}{\sqrt{\operatorname{var}(S)}} \text { if } S>0 \\
0 \text { if } S=0 \\
\frac{S+1}{\sqrt{\operatorname{var}(S)}} \text { if } S<0
\end{array}\right\}
$$

235

236

The $Z$ value supports in assessing the numerical significance of the trend. If $Z>Z \alpha / 2$, then the trend is judged significant.

\subsection{Cluster analysis}

The cluster analysis is multiple advanced techniques, which group components into clusters as per to the high connection of their characteristics like homogenous similarity and other geographical-physical features (Zolfaghari et al. 2019). For this study, we have used agglomerative hierarchical clustering (AHC), which is also called the "bottom-up" method. In this, all the stored observations make their cluster and merge until all similar information cluster in one. Several recent (Hu et al., 2019; Jaya et al., 2020) studies have used this clustering and indicated that this method is much easier to utilize. Some important applications using the clustering method were discussed in Bouguettaya et al. 2015. We have calculated the AHC using XLSTAT and SPSS v 17.0 software and measured by Ward's method (Ward \& Hook, 1963) and Euclidean distance (Everitt and Dunn 1991) in Equation 5:

$$
d_{e}=\left[\sum_{i=1}^{n}\left(Q_{a, i}-Q_{b, i}\right)\right]^{1 / 2}
$$

Where,

$$
d e=\text { Euclidean distance; and }
$$

$Q_{a, i}$ and $Q_{b, i}=$ quantitative component $i$ of individuals $a$ and $b$ 
In this study, the trendiest method i.e. silhouette coefficient (SC) utilized to determine the best possible number of clusters. Zhu et al., 2010 discussed more this method. For different clusters, the values of silhouette $S(i)$ are computed by using Equation 6 (Rousseeuw 1987).

$$
S(i)=\frac{b(i)-a(i)}{\max [a(i), b(i)]}
$$

Where $a(i)$ and $b(i)$ are the mean difference of two different clusters.

To verify a correct number of cluster $c$, averaging of all $S(i)$ values for every $c$ was done to obtain the average silhouette coefficient $\mathrm{s}(c), c=2,3, \ldots, n-1$ for all objects. After that, a specific digit of clusters $c$ is determined which relates to the topmost value of the average silhouette coefficient.

\subsection{Continuous wavelets transform}

The wavelet transform is comparatively a new method for multiple time series analysis in the field of hydrology (Sang 2013). One of the most used methods to analyze periodicity is continuous wavelet transform (CWT). Under this study, CWT edifying time-series attributes in multi-temporal scales to obtain periodicity of precipitation (Rashid et al. 2015). Further, we don't want Fourier transform (FT) because it just provides us the global frequency, but to analyze dynamic features we need localized variability in frequency with temporal details. Hence, CWT is applied to convert the time domain to frequency domain which simply works in a change of basis with signal domain (Joshi et al. 2016). CWT is calculated using Equation (7) by Abdourahamane \& Acar 2018.

$$
W_{f}(a, b)=\frac{1}{\sqrt{a}} \int_{-\infty}^{\infty} f(t) e^{i c\left(\frac{t-b}{a}\right)} e^{\frac{t}{a}\left(\frac{t-b}{a}\right)^{2}} d t
$$

Where,

$$
W_{f}(a, b) \text { - wavelet coefficient }
$$

$a$ - periodic level of wavelet

$b$ - time-digit

$i$ - imaginary digit

$c$ - constant 
289 Further, to detect periodicity in seasonal precipitation, the Morlet wavelet was applied under

290 CWT(Han et al., 2021). The Morlet wavelet was computed by Jones et al. (2015) as Equation 2918 :

292

$$
\widehat{\psi}_{0}(S W)=\pi^{1 / 4} \mathrm{H}(\omega) e^{-\left(s \omega-\omega_{0}\right) 2 / 2}
$$

294

295

296

297

Where,

$$
\begin{aligned}
& s \text { - wavelet stage } \\
& \omega \text { - frequency } \\
& H(\omega) \text { - Heaviside step function } \\
& \varphi_{0} \text { - non-dimensional frequency }
\end{aligned}
$$

However, the pairwise wavelet coherence could essentially explain periodic strength between and interdependence with two different features. Moreover, the characteristics of the hydrodynamic climate variable can be delineated, with recurrent and periodic followed by certain regular intervals.

\section{Result and discussions}

\subsection{Descriptive statistics of rainfall}

The average yearly rainfall over the entire Mahi basin was $904.6 \mathrm{~mm}$ from 1970 to 2020, with a standard variation of $292.9 \mathrm{~mm}$ and variability extent to mean $32.4 \%$ as shown in Table 3 . The overall statistical analysis revealed that the lowest rainfall was observed in1974 and 2000 i.e. $474.9 \mathrm{~mm}$ which means the driest year, while the highest was recorded in 1976 i.e. $1647.7 \mathrm{~mm}$ very wettest year from 1970 to 2020 over the entire Mahi basin. The coefficient of variation (CV) of the datasets indicates low i.e. $42.4 \%$ (heavy rainfall) to high i.e. 523.6\% (low rainfall) deviation of distribution with an average value of $32.4 \%$. These analyses are consistent with the studies of Panda \& Sahu, 2019 and Das et al., 2021 which evaluate seasonal rainfall features with some statistics. 
Table 3: Statistical information of rainfall in Mahi River Basin, India during the period 1970 to 2020

In the basin, JJAS contributes maximum rainy months about the highest percentage (94.7\%) of the total rainfall which indicates extreme rainfall as depicted in Figure 3-A. Also, it was observed that nearly 30 to $34 \%$ of rainfall was received during July and August, while approx. $12 \%$ in June and September months. On the other hand, very low rainfall was observed in February to April/May over the entire Mahi basin around $0.5 \%$ of the total rainfall. The mean annual rainfall and 5-year moving average have been calculated from 1970 to 2020 as shown in Figure 3-B. The results show a high variability every year in the last 50 years. The longterm rainfall data of 51 years revealed the decline in the average annual rainfall trend line. Although the rainfall in 1976 and 2007 is very high approx. $1550-1600 \mathrm{~mm}$. After 2007, the result of moving average shows a declining trend of rainfall up to 2018 as shown in Figure 3B.

Figure 3: Mean rainfall (mm) over Mahi River Basin during the period 1970 to 2020. (A) Monthly and (B) Annual rainfall along with a 5-year moving average

\subsection{Precipitation trend - elevation analysis}

Figure 4 shows the relationship between seasonal rainfall with an elevation over the basin. It was observed that higher elevation or hilly areas have a significant effect on rainfall in different seasons. Figure 4 plots a line-scatter diagram illustrating the relationship between precipitation and elevation for the 1970 to 2020 period using IMD observational data. The winter and premonsoon followed by post-monsoon seasons received low rainfall showing an increasing trend line with elevation. The relationship $b / w$ these three seasons is not linear. During winter at high elevation, cold air is unable to hold water vapor before touch saturation level, hence rain lots in these seasons. On other hand, as per the previous results (Figure 3-A), Monsoon months received more rainfall and shows decreasing pattern of the trend line with elevation as shown in Figure 4.

Figure 4: Relationship of seasonal precipitation (winter, pre-monsoon, monsoon, and postmonsoon) and elevation in the Mahi River Basin during the period 1970 to 2020 
351 For arriving at clear conclusions about seasonal rainfall related to climate change, trend analysis is necessary as it provides a sense of the events/activities that have occurred in the past. With the help of trend analysis (MK trend test), we can understand present climatic conditions and predict future scenarios easily. In the present study, seasonal trend analysis of precipitation is analyzed for 51 grid locations in the basin and their results are summarized in Table 4. The result of the trend for all seasons shows a non-significant decreasing pattern. The average pvalue is 0.3724 and the trends have no significance for the entire river basin. Overall, the seasonal trend and relationship with elevation were also carried by Yao et al. 2016 and Hu et al. 2019.

Table 4: Significance test of seasonal rainfall using Mann-Kendall in the Mahi River Basin, India

\subsection{Seasonal precipitation regionalization}

For regionalization of seasonal precipitation, HCA has been applied to classify the IMD grids point over the Mahi River basin. After that, we have computed the silhouette coefficient method, which determined the best possible number of clusters for seasonal precipitation. The value of the coefficient gives a total of 10 different clusters i.e. 1 to 10 which are presented in Figure 5 A-D. For monsoon season, the IMD grid points partition into 4 clusters because it has the highest average value of SC, which highlights inter-cluster similarity and dis-similarity $\mathrm{b} / \mathrm{w}$ the clusters as shown in figure 5-B. On the other hand, the highest value obtained for the other three seasons is 3 , which means it cluster IMD grid points into 3 groups as represented in figure 5 A, C, and D. Similarly study by Durand \& Daneshvar 2014 and Vijith Dodge-Wan 2019 also used the Hierarchical Clustering in a different region for rainfall analysis.

Figure 5: Average silhouette values as per the IMD seasons (a) Pre-Monsoon, (b) Monsoon, (c) Post-Monsoon, and (d) Winter for different numbers of clusters

Similarly, the spatial plots of seasonal precipitation regionalization using IMD seasons over the Mahi River basin are shown in Figure 6. As shown in Figure 6-B, monsoon season is divided into four subregions: JJAS1, JJAS2, JJAS3, and JJAS4. Similarly for other three seasons i.e. 
pre-monsoon, winter, and post-monsoon classified into three subregions as shown in Figure 6. The number of IMD grids points, codes, and their mean precipitation for every single cluster in all the seasons are presented in Table 4. In the monsoon season, the JJAS1 has the highest grids points (16) with a mean rainfall of $929.27 \mathrm{~mm}$, cover the southwest part of the Mahi River basin i.e. area of Madhya Pradesh. Similar results in Langat River Basin, Malaysia was found by previous research work of Palizdan et al. 2017. Also, similar study in western Rajasthan was carried out by Machiwal et al. 2019 using HCA.

Table 5: The number of points and average precipitation for each of the clusters in 4 IMD seasons

Figure 6: Spatial plot showing the regionalization (Clusters) of seasonal precipitation in the 4 IMD seasons over the Mahi River basin, India

\subsection{Periodicity and wavelet coherence}

This section details the bivariate spectral relationship between four seasonally dynamic features Winter, Pre-monsoon, Monsoon, and Post-Monsoon. Figure 7 (A-F) represents the crosswavelet spectrum using CWT and Morlet wavelet using R as a base programming language. Utilizing scalogram/cross wavelet spectrum that is shown in Figures 7 A-F, image wavelet analysis is used which detects the reconstruction cycles over the full reconstruction period, the significance with $\mathrm{p}>0.05$ is shown in white polygon lines with adjusted base colour band scale levels in interval basis starting from 0 to 1.8 in approx. as they get vary according to the precipitation level of intensity, the ranges indicating colours of red for high and blue for low. The arrow with the white contour line indicates the area of joint significance at a $10 \%$ level. The parabolic curve with diminished colour is a cone of influence (COI) that ignores the edge effect artifacts that extend wavelets except for the region of interest. The scalogram image has continuous variation in strength and temporal level, so the discussion will be semi qualitative representing appropriate ranges. A similar method of periodicity identification was carried out in semi-arid regions of northwest China (Han et al. 2021).

Figure 7: Continuous cross wavelet spectrum within inter-seasonal precipitation over Mahi River basin, India 
Relationship with Winter and Pre-monsoon shows the good significance at 2 years to 4 years period for the year 1970 to 1980, the significant periods are increasing and for a year between 1995 and 2000 also there is minimal increase found (Figure 7-A). A strong significant correlation is found with periodic period 2 - 4 years at the year $1974-1978$ with divergence in phase variation with periodic temporal scale, this may be due to the sequential internal effect of post-monsoon as the relation between post-monsoon and winter also indicated the similar pattern, this part partially provides an idea that there is inducing relativity of decrease in precipitation with winter, monsoon, and post-monsoon (Figure 7-B).

423

A lot of discrete pack of the significant patched pattern is found when we relate Post-Monsoon and Winter, strong correlation within 1975 - 1980 (decreasing), 1985 - 1987 (decreasing), and 2013 - 2019 (increasing) indicating an oscillatory relationship. Low/moderate level correlation with significance in increasing trend found at time periodicity of 3 - 4 years near 1975 - 1980 (Figure 7-C). On Monsoon and post-monsoon, there is a significant relationship found between the year 1975 - 1987 but the phase variation is with high values towards the previous year, indicating yearly rising and but with a sudden drop in peak values. Considering the overall scenario neglecting the significance, the green colour band confirms our internal and instantaneous correlation in period 2 - 4 years although some continuity patchy breaks are found in a certain year. As well when the time wavelet is stretched to 14 - 16 period year a significant rise tending from 2005 to 1980 confirming a periodic variation in reversive fallback (Figure 7D).

With Pre-monsoon and Monsoon, the significant instantaneous variation is found at period 2 to 4 years but some significant correlation between 1973 - 1987 with increasing rate and 1990 2015 with decreasing indicating an inter-seasonal correlation when the period is stretched to 8 years (Figure 7-E). Discussing the significant part for Pre-Monsoon and Post-Monsoon, a complete diversified and opposite relationship is found when the periodic period is stretched which is found at periodic time $2-4$. The year 1975 - 1990 indicating the reduction in wet spells and increase in a dry spell and it is well clear that their relationship is more adapt in a case on instantaneous periodicity i.e., with small stretch in periodic time scale (Figure 7-F). Overall, these findings are somehow consistent with the studies of Ruwangika \& Rathnayake 2020 and Pandey et al. 2017 which analyzed seasonal rainfall using the wavelet transform method. 


\section{Conclusions}

The present study explored the inter-seasonal rainfall trends and periodicities over the Mahi River basin from 1970 to 2020 . From the result of statistical time series analysis, it was observed that in the basin the maximum rainfall received in monsoon seasons (JJAS), while winter and pre-monsoon provide a considerably less amount of rainfall. Only the monsoon season rainfall is extremely intense, from which July and August alone cover $>1 / 2$ of the total rainfall. Due to this, sometimes the pre-monsoon months were badly affected by a thunderstorm, which caused extreme drought conditions, and prolonged risk of dry spells over the study region. We investigated that the precipitation trend-elevation relationship and found that, the season with heavy rainfall shows decreasing pattern trend with increasing elevation because some parts of the basin cover with Aravalli hills which act as an enclosed boundary to southwest winds approaching from the Arabian sea. The heating of the Arabian Sea and tropospheric-warming, which lead to the movement of the low-level jet stream toward the upper region of the basin. Whereas the result of the non-parametric Mann-Kendall test also shows non-significant decreasing trends for all seasons of rainfall in the Mahi basin.

Moreover, the regionalization and periodicity of seasonal precipitation were carried out using HCA and CWT respectively. The results obtained from HCA cluster the seasonal precipitation based on similar precipitation and geographical information. From the analysis, it was found that monsoon precipitation sub-groups into 4 clusters, while in the case of the rest of the seasons it sub-groups into 3 clusters for the entire basin. These formed clusters have strong coherent features. The main finding of the CWT summarized a strong significant correlation is found between winter and monsoon season. These results indicate the dominant and persistent oscillation with retrospection in seasonal relationships. The outcomes for the entire basin highlight that, higher altitude or hilly areas have a significant effect and experienced moderate to heavy rainfall due to moisture convergence and temperature variation. Overall results concluded some significant information about periodicities that affect seasonal precipitation trends. This information may help to better understand the future forecast trend of precipitation and agriculture productivity over the entire Mahi basin. However, it is noted that the physical mechanism and possible influence of atmospheric circulations on precipitation are still needed for future analysis. 


\section{CRediT authorship contribution statement}

Aditya Sharma: Conceptualization, Data curation, Formal analysis, Investigation, Methodology, Software, Visualization, Roles/Writing - original draft, Writing - review \& editing; Devesh Sharma: Conceptualization, Resources, Supervision, Writing - review \& editing. Shyam Sunder MS: Conceptualization, Formal analysis, Visualization, Writing review \& editing.

\section{Acknowledgments}

The authors are grateful to the Indian Meteorological Department and National Data Centre, Pune for providing the datasets for the research. The authors also thank the anonymous reviewers as well as Editor in Chief and Associate Editor for the thorough assessment of the present paper, and their valuable comments and suggestions that helped to improve this paper.

\section{References}

Abdourahamane, Z. S., \& Acar, R. (2018). Analysis of meteorological drought variability in Niger and its connection with climate indices. Hydrological Sciences Journal, 63(8), 1203-1218.

Alam, M. S., \& Paul, S. (2020). A comparative analysis of clustering algorithms to identify the homogeneous rainfall gauge stations of Bangladesh. Journal of Applied Statistics, 47(8), 1460-1481.

Alemu, Z. A., \& Dioha, M. O. (2020). Climate change and trend analysis of temperature: the case of Addis Ababa, Ethiopia. Environmental Systems Research, 9(1), 1-15.

Amato, F., Guignard, F., Robert, S., \& Kanevski, M. (2020). A novel framework for spatiotemporal prediction of environmental data using deep learning. Scientific reports, 10(1), $1-11$.

Boretti, A., \& Rosa, L. (2019). Reassessing the projections of the world water development report. NPJ Clean Water, 2(1), 1-6. 
Bouguettaya, A., Yu, Q., Liu, X., Zhou, X., \& Song, A. (2015). Efficient agglomerative hierarchical clustering. Expert Systems with Applications, 42(5), 2785-2797.

Cerón, W. L., Molina-Carpio, J., Ayes Rivera, I., Andreoli, R. V., Kayano, M. T., \& Canchala, T. (2020). A principal component analysis approach to assess CHIRPS precipitation dataset for the study of climate variability of the La Plata Basin, Southern South America. Natural Hazards, 103(1).

CHINCHORKAR, S. (2020). Long-term trend analysis of rainfall using hybrid Discrete Wavelet Transform (DWT) based Mann-Kendall tests in central Gujarat region, India. MAUSAM, 71(2), 209-224.

Darand, M., \& Daneshvar, M. R. M. (2014). Regionalization of precipitation regimes in Iran using principal component analysis and hierarchical clustering analysis. Environmental Processes, 1(4), 517-532.

Das, J., Mandal, T., Rahman, A. S., \& Saha, P. (2021). Spatio-temporal characterization of rainfall in Bangladesh: an innovative trend and discrete wavelet transformation approaches. Theoretical and Applied Climatology, 143(3), 1557-1579.

Döll, P., Jiménez-Cisneros, B., Oki, T., Arnell, N. W., Benito, G., Cogley, J. G., ... \& Nishijima, A. (2015). Integrating risks of climate change into water management. Hydrological Sciences Journal, 60(1), 4-13.

Everitt, B. S., \& Dunn, G. (1991). Applied multivariate data analysis (No. 519.5076 E9).

Feng, G., Cobb, S., Abdo, Z., Fisher, D. K., Ouyang, Y., Adeli, A., \& Jenkins, J. N. (2016). Trend analysis and forecast of precipitation, reference evapotranspiration, and rainfall deficit in the Blackland Prairie of Eastern Mississippi. Journal of Applied Meteorology and Climatology, 55(7), 1425-1439.

Ghaedi, S., \& Shojaian, A. (2020). Spatial and temporal variability of precipitation concentration in Iran. Geographica Pannonica, 24(4).

Gupta, N., \& Chavan, S. (2021, April). Spatio-temporal characterization of rainfall using an innovative trend and discrete wavelet transformation approaches in Bhakra catchment, India. In EGU General Assembly Conference Abstracts (pp. EGU21-15857).

Han, H., Hou, J., Jiang, R., Gong, J., Bai, G., Kang, Y., ... \& Li, B. (2021). Spatial and temporal variation of precipitation characteristics in the semiarid region of $\mathrm{Xi}^{\prime}$ an, northwest China. Journal of Water and Climate Change. 
Han, H., Hou, J., Jiang, R., Gong, J., Bai, G., Kang, Y., ... \& Li, B. (2021). Spatial and temporal variation of precipitation characteristics in the semiarid region of $\mathrm{Xi}^{\prime}$ an, northwest China. Journal of Water and Climate Change.

Hochman, A., Saaroni, H., Abramovich, F., \& Alpert, P. (2019). Artificial Detection of LowerFrequency Periodicity in Climatic Studies by Wavelet Analysis Demonstrated on Synthetic Time Series. Journal of Applied Meteorology and Climatology, 58(9), 20772086.

Hock, R., Rasul, G., Adler, C., Cáceres, B., Gruber, S., Hirabayashi, Y., ... \& Zhang, Y. (2019). High mountain areas. https://www.ipcc.ch/srocc/chapter/chapter-2/

Hoegh-Guldberg, O., Jacob, D., Bindi, M., Brown, S., Camilloni, I., Diedhiou, A., ... \& Zougmoré, R. B. (2018). Impacts of $1.5 \mathrm{C}$ global warming on natural and human systems. Global warming of 1.5 C. An IPCC Special Report.

Hu, Q., He, X., Lu, X. A., \& Zhang, X. (2019). Trend Analysis of seasonal precipitation (19602013) in SUBREGIONS Of Hunan Province, Central South China using discrete wavelet transforms. Journal of Applied Meteorology and Climatology, 58(10), 21592175 .

Huang, Y., Yi, L., Xiao, W., Hou, G., \& Zhou, Y. (2021). Spatiotemporal variation characteristics of extreme precipitation in the upper reaches of the Hongshui River Basin during 1959-2016. Journal of Water and Climate Change.

Jaya, I. G. N. M., \& Folmer, H. (2020). Identifying spatiotemporal clusters by means of agglomerative hierarchical clustering and Bayesian regression analysis with spatiotemporally varying coefficients: methodology and application to dengue disease in Bandung, Indonesia. Geographical Analysis.

Jeelani, G., Feddema, J. J., van der Veen, C. J., \& Stearns, L. (2012). Role of snow and glacier melt in controlling river hydrology in Liddar watershed (western Himalaya) under current and future climate. Water Resources Research, 48(12).

Jones, J. R., Schwartz, J. S., Ellis, K. N., Hathaway, J. M., \& Jawdy, C. M. (2015). Temporal variability of precipitation in the Upper Tennessee Valley. Journal of Hydrology: Regional Studies, 3, 125-138. 
Joshi, N., Gupta, D., Suryavanshi, S., Adamowski, J., \& Madramootoo, C. A. (2016). Analysis of trends and dominant periodicities in drought variables in India: a wavelet transform based approach. Atmospheric Research, 182, 200-220.

Kumar, V., Jain, S. K., \& Singh, Y. (2010). Analysis of long-term rainfall trends in India. Hydrological Sciences Journal, 55(4), 484-96.

Loucks, D. P., \& van Beek, E. (2017). Water resources planning and management: An overview. Water Resource Systems Planning and Management, 1-49.

Lv, X., Zuo, Z., Ni, Y., Sun, J., \& Wang, H. (2019). The effects of climate and catchment characteristic change on streamflow in a typical tributary of the Yellow River. Scientific reports, 9(1), 1-10.

Machiwal, D., Kumar, S., Meena, H. M., Santra, P., Singh, R. K., \& Singh, D. V. (2019). Clustering of rainfall stations and distinguishing influential factors using PCA and HCA techniques over the western dry region of India. Meteorological Applications, 26(2), $300-311$.

Mar, S., Nomura, H., Takahashi, Y., Ogata, K., \& Yabe, M. (2018). Impact of erratic rainfall from climate change on pulse production efficiency in lower Myanmar. Sustainability, $10(2), 402$.

Masson-Delmotte, V., Zhai, P., Pörtner, H. O., Roberts, D., Skea, J., Shukla, P. R., ... \& Waterfield, T. (2018). Global warming of 1.5 C. An IPCC Special Report on the impacts of global warming of, 1, 1-9.

Maurya, S., Srivastava, P. K., Yaduvanshi, A., Anand, A., Petropoulos, G. P., Zhuo, L., \& Mall, R. K. (2021). Soil erosion in future scenario using CMIP5 models and earth observation datasets. Journal of Hydrology, 594, 125851.

Moni, D. R., Patasaraiya, M. K., Bhaskar, S., Jigyasa, B., \& Dimri, A. P. (2020). Analyzing precipitation and temperature trends of Kanha and Satpura Tiger Reserve, Central India. Theoretical and Applied Climatology, 140(3-4), 1435-1450.

MoWR (2014). Mahi Basin. Central Water Commission (CWC) and National Remote Sensing Centre (NRSC), Indian Space Research Organisation (ISRO).

Nisansala, W. D. S., Abeysingha, N. S., Islam, A., \& Bandara, A. M. K. R. (2020). Recent rainfall trend over Sri Lanka (1987-2017). International Journal of Climatology, 40(7), $3417-3435$. 
Oppenheimer, M., B.C. Glavovic , J. Hinkel, R. van de Wal,.....\& Z. Sebesvari, 2019: Sea Level Rise and Implications for Low-Lying Islands, Coasts and Communities. In: IPCC Special Report on the Ocean and Cryosphere in a Changing Climate [H.-O. Pörtner, D.C. Roberts, V. Masson-Delmotte, ....\& B. Rama, N.M. Weyer (eds.)]. In press

Othman, M., Ash'aari, Z. H., \& Mohamad, N. D. (2015). Long-term daily rainfall pattern recognition: Application of principal component analysis. Procedia Environmental Sciences, 30, 127-132.

Palizdan, N., Falamarzi, Y., Huang, Y. F., \& Lee, T. S. (2017). Precipitation trend analysis using discrete wavelet transform at the Langat River Basin, Selangor, Malaysia. Stochastic Environmental Research and Risk Assessment, 31(4), 853-877.

Palizdan, N., Falamarzi, Y., Huang, Y. F., \& Lee, T. S. (2017). Precipitation trend analysis using discrete wavelet transform at the Langat River Basin, Selangor, Malaysia. Stochastic Environmental Research and Risk Assessment, 31(4), 853-877.

Panda, A., \& Sahu, N. (2019). Trend analysis of seasonal rainfall and temperature pattern in Kalahandi, Bolangir and Koraput districts of Odisha, India. Atmospheric Science Letters, 20(10), e932.

Pandey, B. K., Tiwari, H., \& Khare, D. (2017). Trend analysis using discrete wavelet transform (DWT) for long-term precipitation (1851-2006) over India. Hydrological sciences journal, 62(13), 2187-2208.

Pawar, U., \& Hire, P. (2018). Flood Frequency Analysis of the Mahi Basin by Using Log 822 Pearson Type III Probability Distribution.

Pradhan, R. K., Sharma, D., Panda, S. K., Dubey, S. K., \& Sharma, A. (2019). Changes of precipitation regime and its indices over Rajasthan state of India: impact of climate change scenarios experiments. Climate Dynamics, 52(5), 3405-3420.

Praveen, B., Talukdar, S., Mahato, S., Mondal, J., Sharma, P., Islam, A. R. M. T., \& Rahman, A. (2020). Analyzing trend and forecasting of rainfall changes in India using nonparametrical and machine learning approaches. Scientific reports, 10(1), 1-21.

Rai, P., \& Dimri, A. P. (2020). Changes in rainfall seasonality pattern over India. Meteorological Applications, 27(1), e1823.

Rashid, M. M., Beecham, S., \& Chowdhury, R. K. (2015). Assessment of trends in point rainfall using continuous wavelet transforms. Advances in water resources, 82, 1-15. 
Reddy, M. J., \& Adarsh, S. (2016). Time-frequency characterization of sub-divisional scale seasonal rainfall in India using the Hilbert-Huang transform. Stochastic environmental research and risk assessment, 30(4), 1063-1085.

Rousseeuw, P. J. (1987). Silhouettes: a graphical aid to the interpretation and validation of cluster analysis. Journal of computational and applied mathematics, 20, 53-65.

Ruwangika, A. M., Perera, A., \& Rathnayake, U. (2020). Comparison of Statistical, Graphical, and Wavelet Transform Analyses for Rainfall Trends and Patterns in Badulu Oya Catchment, Sri Lanka. Complexity, 2020.

Ruwangika, A. M., Perera, A., \& Rathnayake, U. (2020). Comparison of Statistical, Graphical, and Wavelet Transform Analyses for Rainfall Trends and Patterns in Badulu Oya Catchment, Sri Lanka. Complexity, 2020.

Samra, J. S. (2004). Review and analysis of drought monitoring, declaration and management in India (Vol. 84). IWMI.

Sang, Y. F. (2013). A review on the applications of wavelet transform in hydrology time series analysis. Atmospheric research, 122, 8-15.

Sharma, A., Sharma, D., Panda, S. K., Dubey, S. K., \& Pradhan, R. K. (2018). Investigation of temperature and its indices under climate change scenarios over different regions of Rajasthan state in India. Global and Planetary Change, 161, 82-96.

Sinha, A., Kathayat, G., Cheng, H., Breitenbach, S. F., Berkelhammer, M., Mudelsee, M., ... \& Edwards, R. L. (2015). Trends and oscillations in the Indian summer monsoon rainfall over the last two millennia. Nature communications, 6(1), 1-8.

Srivastava, A.K., Rajeevan, M., Kshirsagar, S.R., 2009. Development of a high resolution daily gridded temperature data set (1969-2005) for the Indian region. Atmos. Sci. Lett. 10 (4), 249-254.

Srivastava, P. K., Pradhan, R. K., Petropoulos, G. P., Pandey, V., Gupta, M., Yaduvanshi, A., ... \& Sahai, A. K. (2021). Long-Term Trend Analysis of Precipitation and Extreme Events over Kosi River Basin in India. Water, 13(12), 1695.

Tabari, H. (2020). Climate change impact on flood and extreme precipitation increases with water availability. Scientific reports, 10(1), 1-10. 
661

662

663

664

665

666

667

668

669

670

671

672

673

674

675

676

677

678

679

680

681

682

683

684

685

686

687

van der Wiel, K., \& Bintanja, R. (2021). Contribution of climatic changes in mean and variability to monthly temperature and precipitation extremes. Communications Earth \& Environment, 2(1), 1-11.

Vijith, H., \& Dodge-Wan, D. (2019). Spatial and temporal characteristics of rainfall over a forested river basin in NW Borneo. Meteorology and Atmospheric Physics, 1-20.

Wang, Y., Xu, Y., Tabari, H., Wang, J., Wang, Q., Song, S., \& Hu, Z. (2020). Innovative trend analysis of annual and seasonal rainfall in the Yangtze River Delta, eastern China. Atmospheric Research, 231, 104673.

Ward Jr, J. H., \& Hook, M. E. (1963). Application of an hierarchical grouping procedure to a problem of grouping profiles. Educational and Psychological Measurement, 23(1), 6981.

Yao, J., Yang, Q., Mao, W., Zhao, Y., \& Xu, X. (2016). Precipitation trend-elevation relationship in arid regions of the China. Global and Planetary Change, 143, 1-9.

Yerdelen, C., Abdelkader, M., \& Eri, E. (2021). Assessment of drought in SPI series using continuous wavelet analysis for GEDIZ basin, Turkey. Atmospheric Research, 105687.

Zamani, R., Mirabbasi, R., Nazeri, M., Meshram, S. G., \& Ahmadi, F. (2018). Spatio-temporal analysis of daily, seasonal and annual precipitation concentration in Jharkhand state, India. Stochastic environmental research and risk assessment, 32(4), 1085-1097.

Zhu, H., He, H., Fan, H., Xu, L., Jiang, J., Jiang, M., \& Xu, Y. (2020). Regional Characteristics of Long-Term Variability of Summer Precipitation in the Poyang Lake Basin and Possible Links with Large-Scale Circulations. Atmosphere, 11(10), 1033.

Zhu, L., Ma, B., \& Zhao, X. (2010). Clustering validity analysis based on silhouette coefficient [J]. Journal of Computer Applications, 30(2), 139-141.

Zolfaghari, F., Khosravi, H., Shahriyari, A., Jabbari, M., \& Abolhasani, A. (2019). Hierarchical cluster analysis to identify the homogeneous desertification management units. PloS one, 14(12), e0226355. 


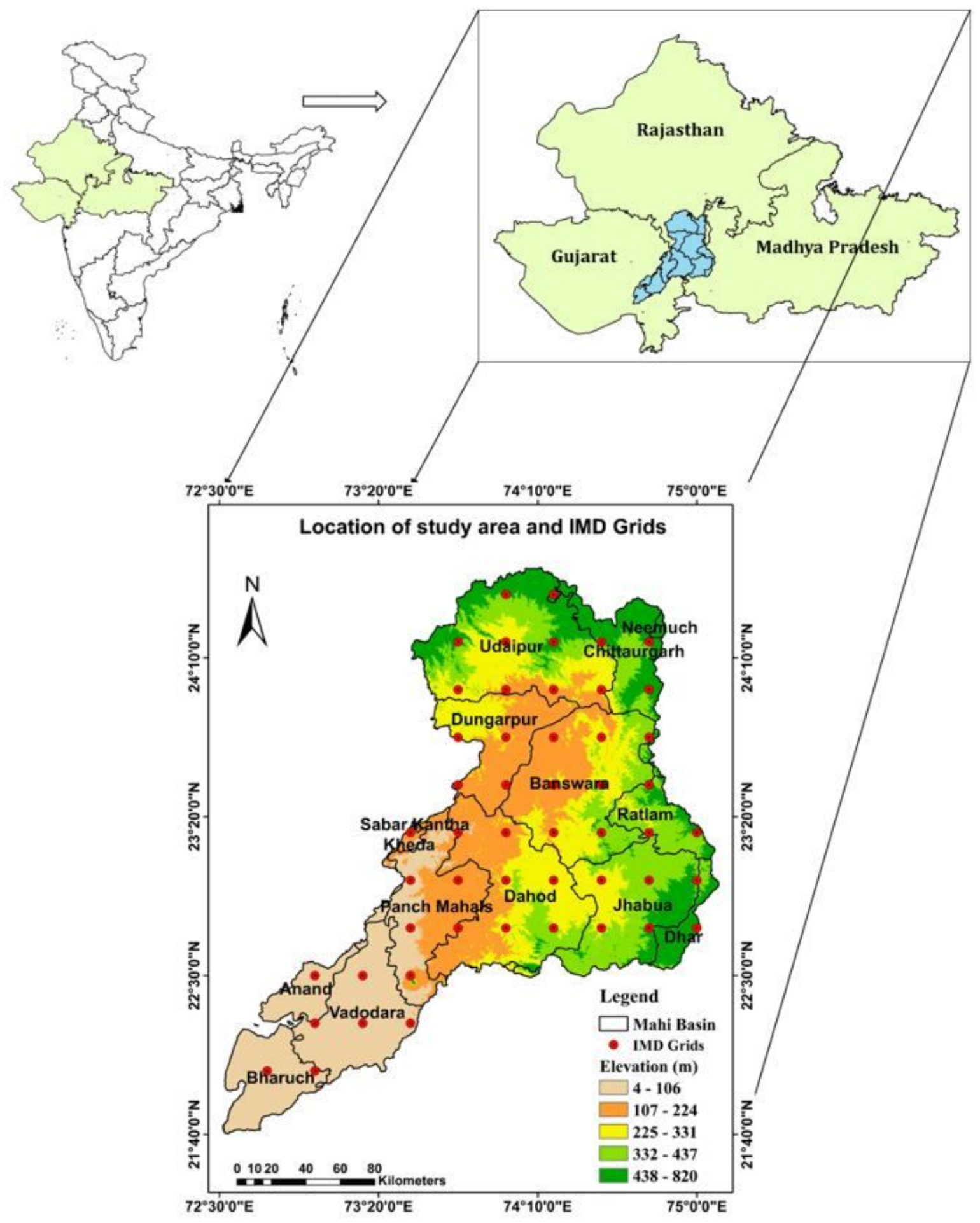

\section{Figure 1}

The geographical location map and IMD gridded points over the Mahi River basin, India 


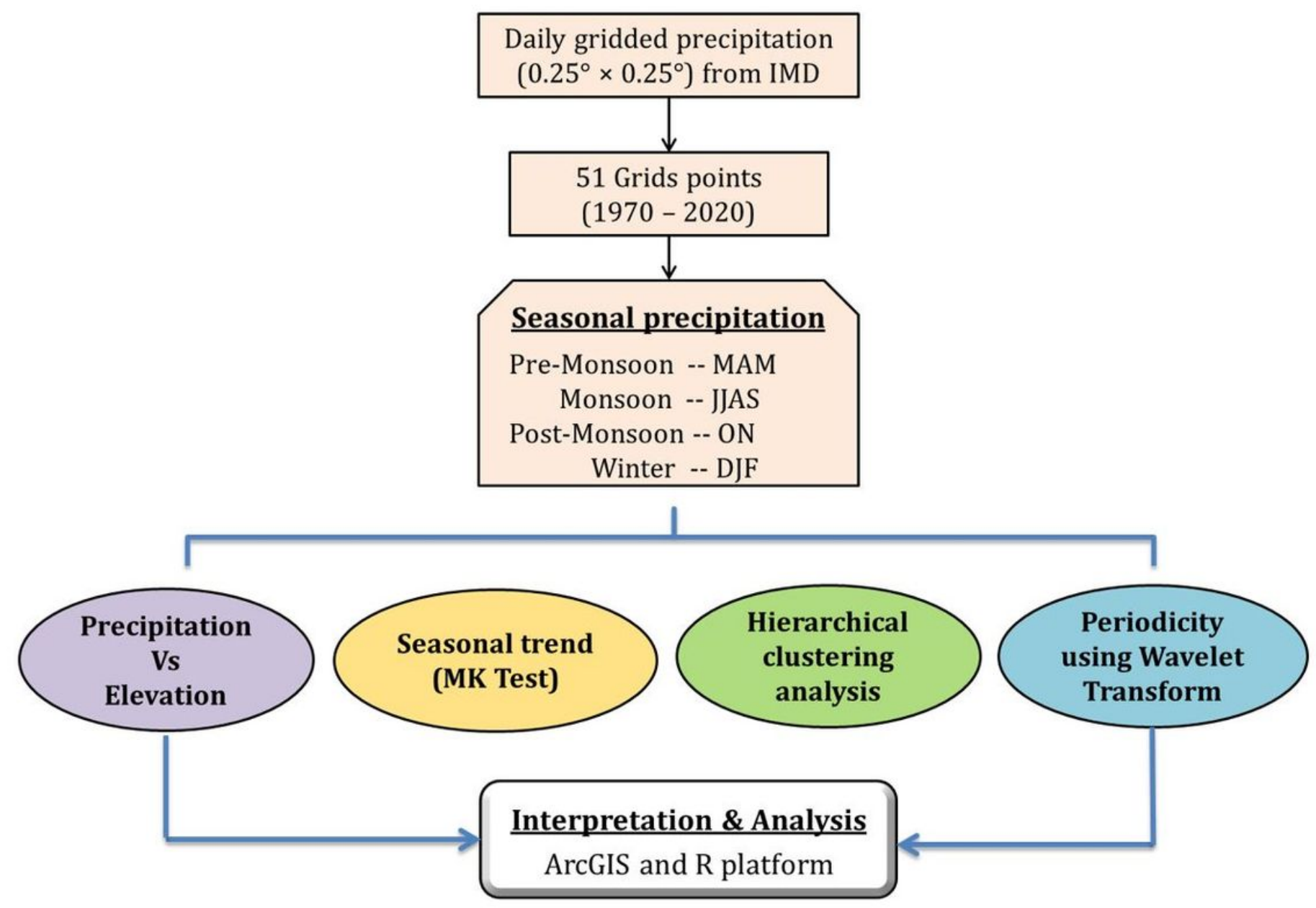

Figure 2

Methodological framework used for the study 

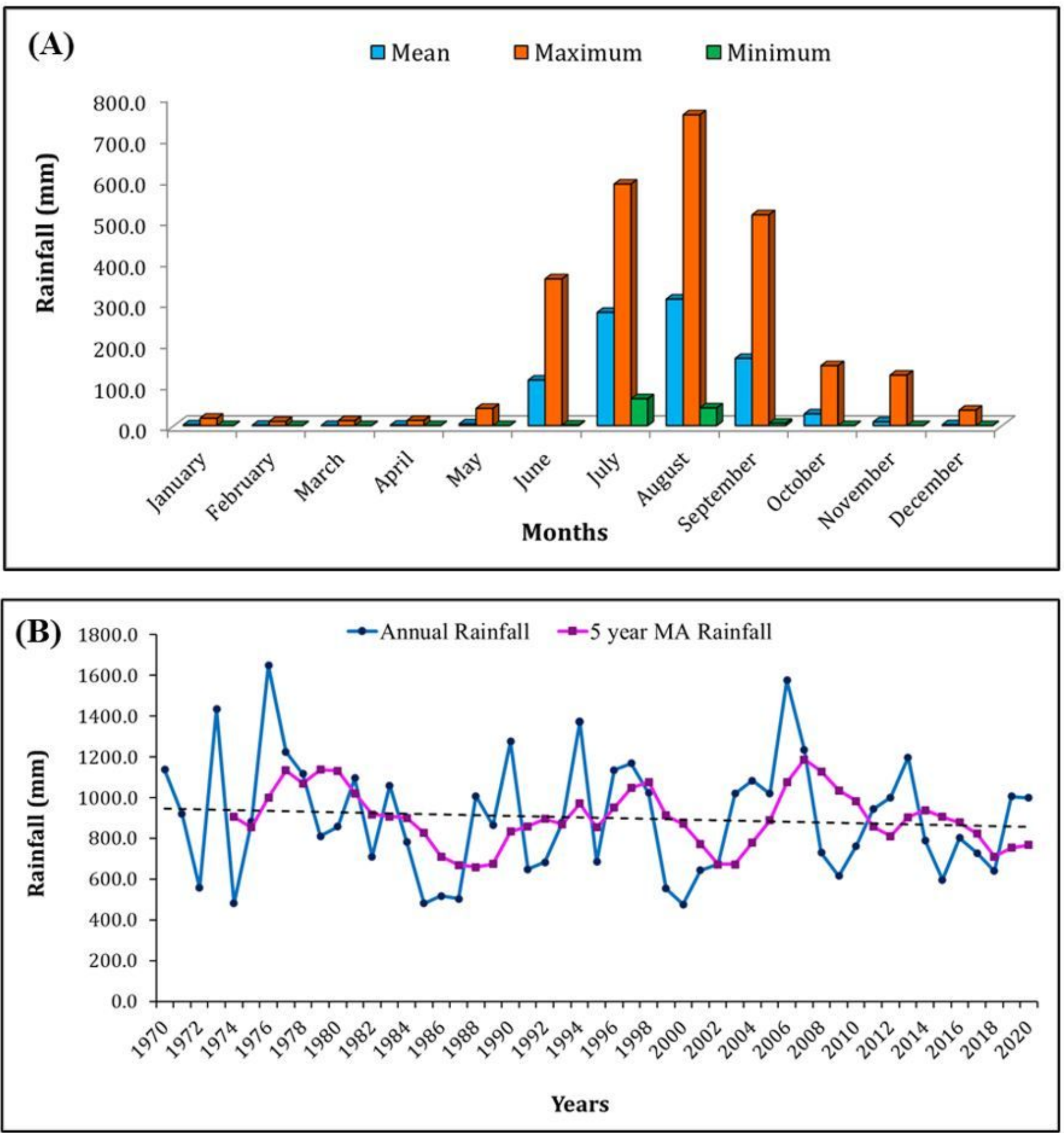

Figure 3

Mean rainfall (mm) over Mahi River Basin during the period 1970 to 2020. (A) Monthly and (B) Annual rainfall along with a 5-year moving average 

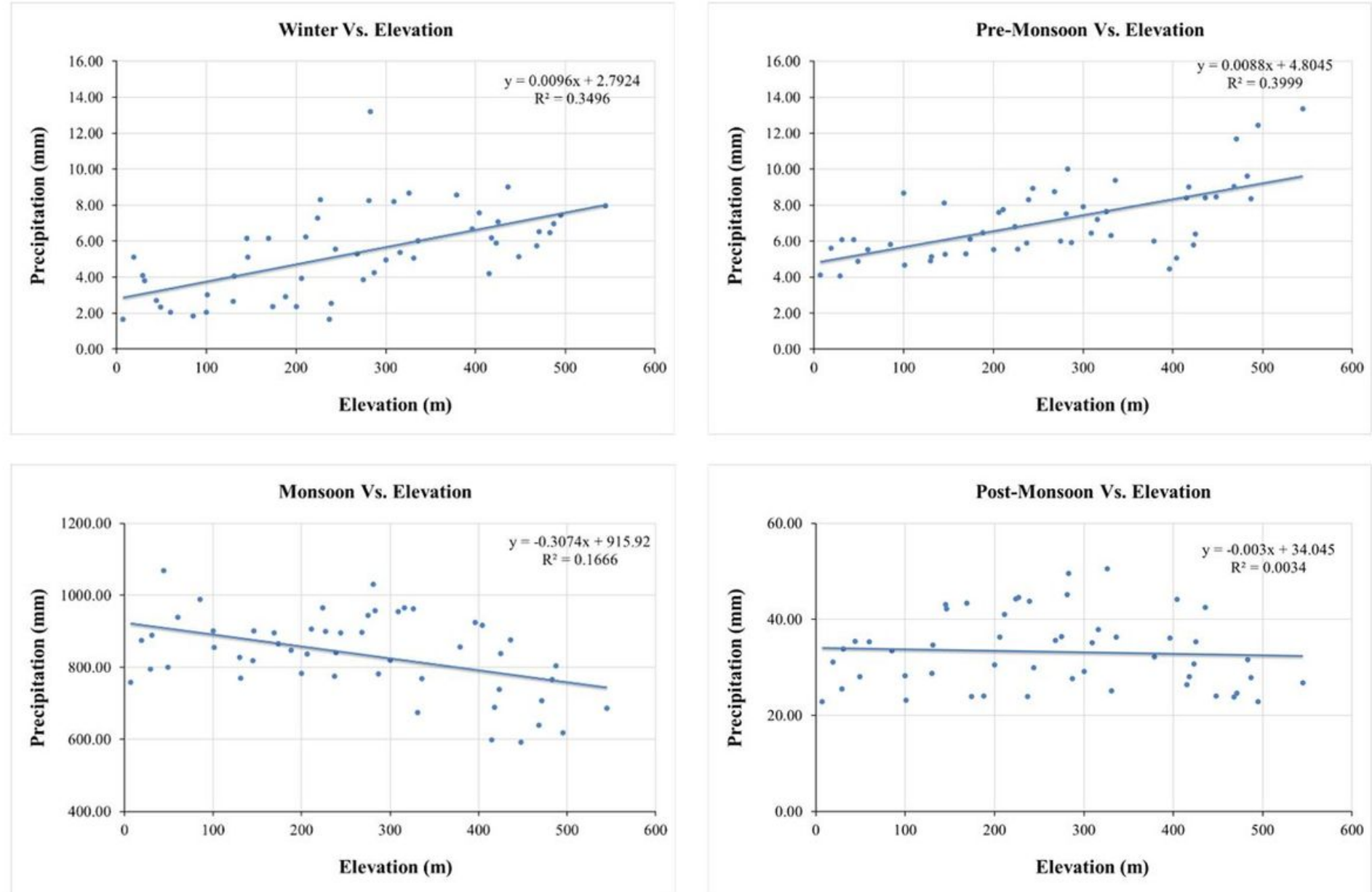

\section{Figure 4}

Relationship of seasonal precipitation (winter, pre-monsoon, monsoon, and post-monsoon) and elevation in the Mahi River Basin during the period 1970 to 2020 

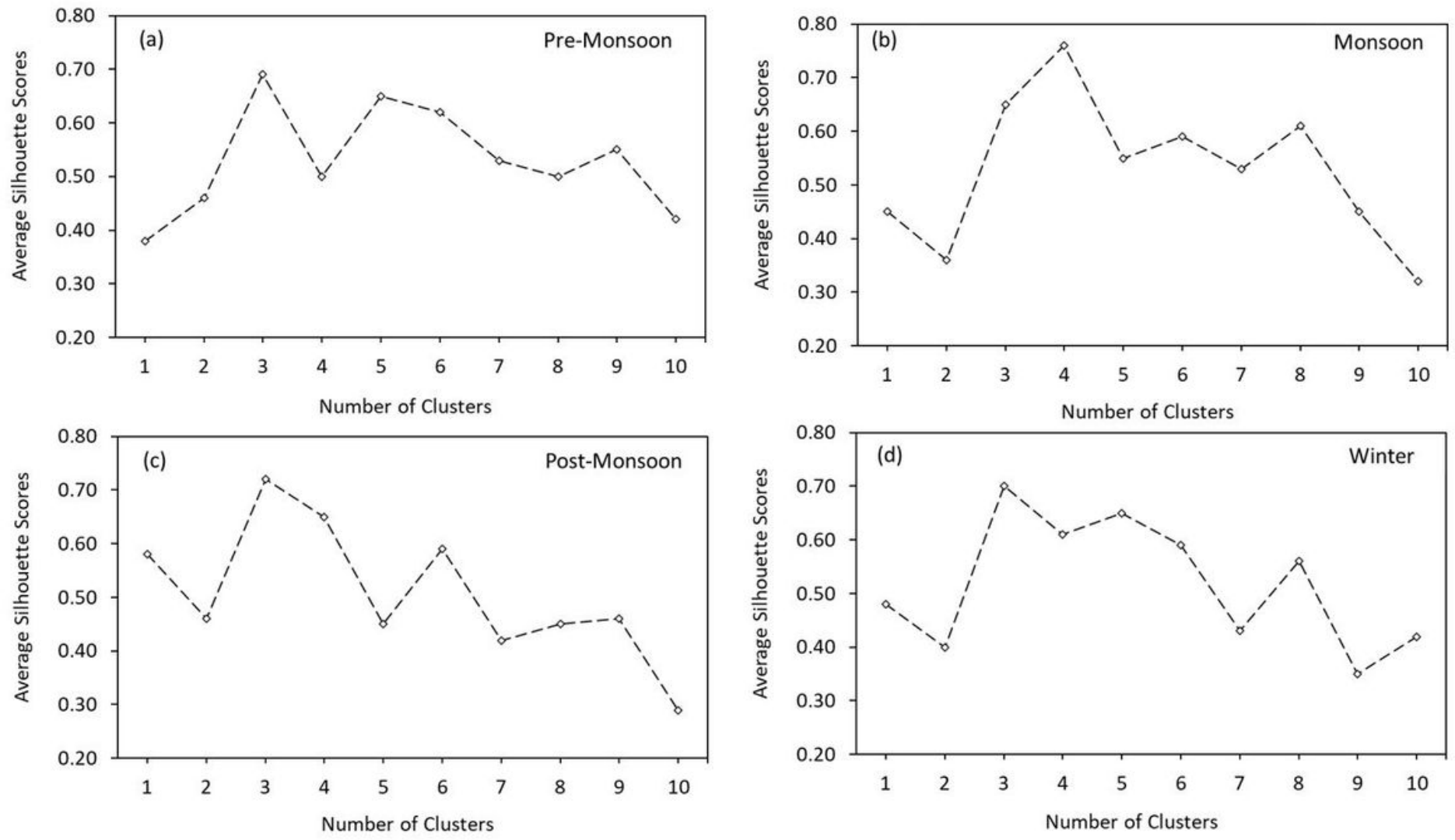

\section{Figure 5}

Average silhouette values as per the IMD seasons (a) Pre-Monsoon, (b) Monsoon, (c) Post-Monsoon, and (d) Winter for different number of clusters 


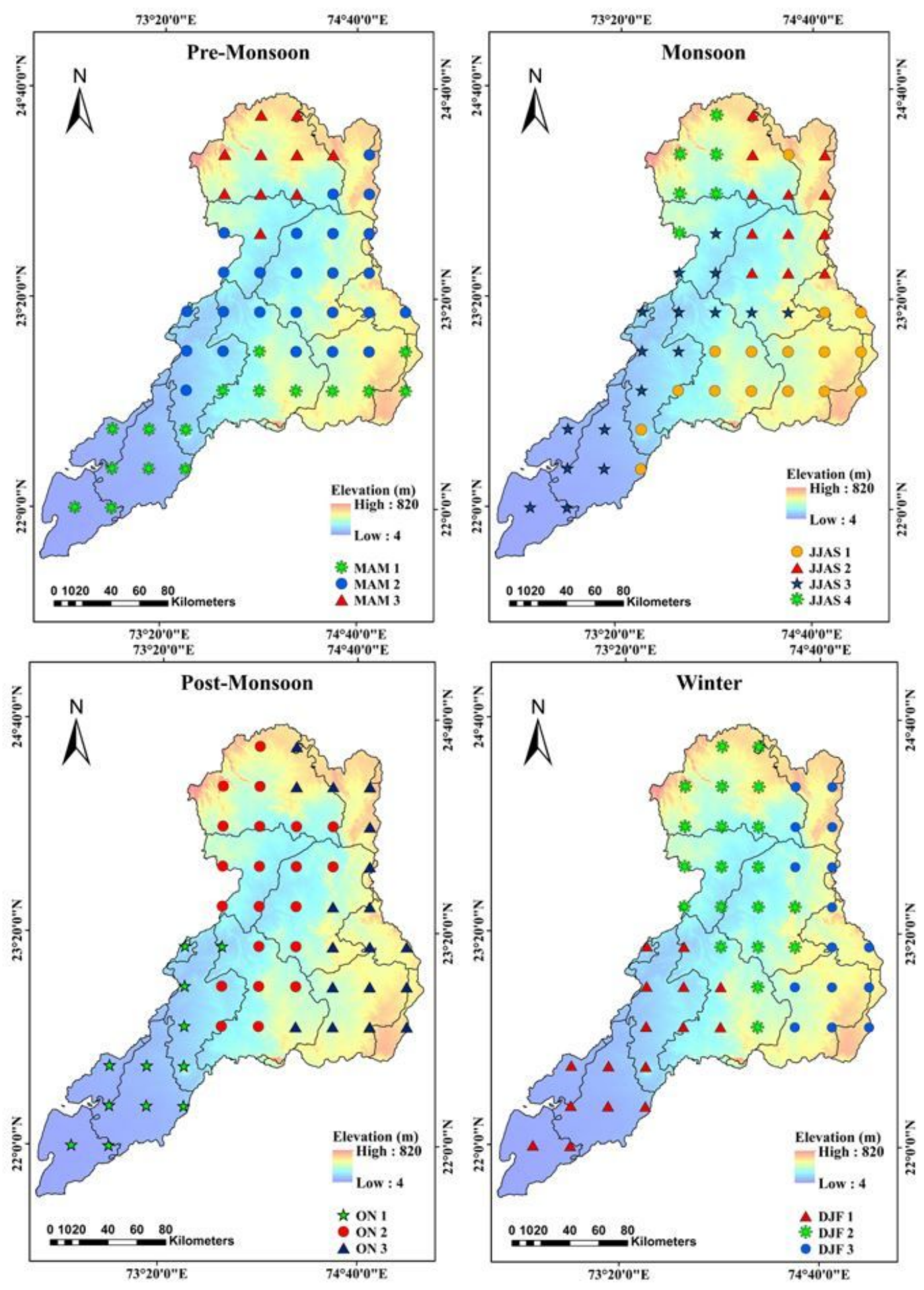

Figure 6

Average silhouette values as per the IMD seasons (a) Pre-Monsoon, (b) Monsoon, (c) Post-Monsoon, and (d) Winter for different numbers of clusters 
(A) Winter \& Pre-Monsoon

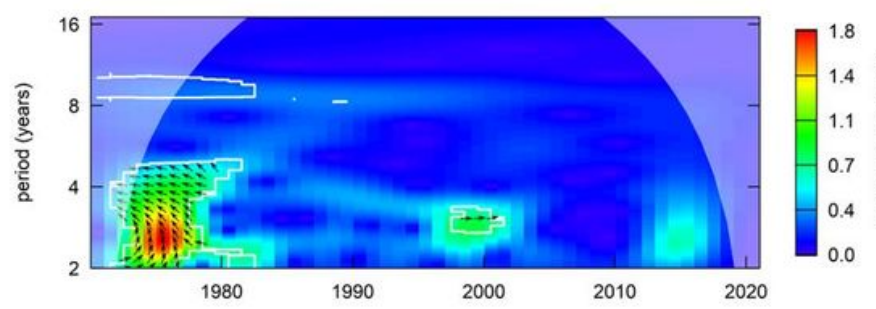

(C) Post-Monsoon \& Winter

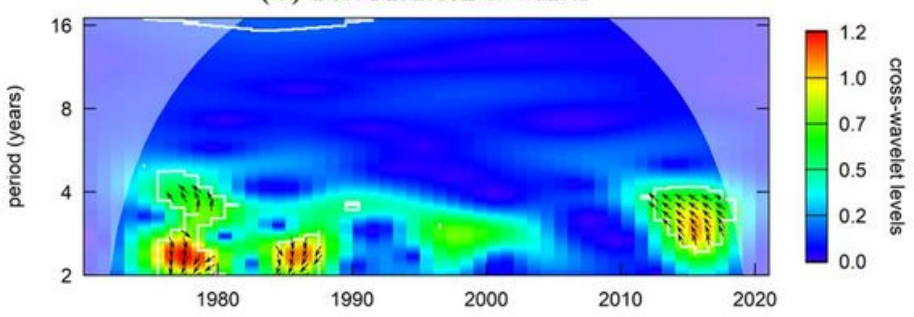

(E) Pre-Monsoon \& Monsoon

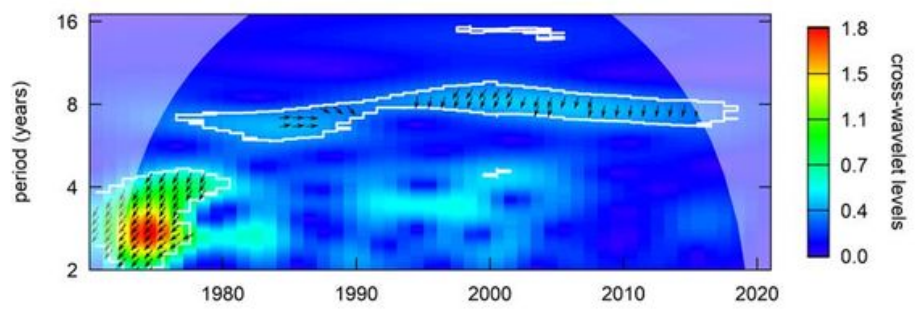

(B) Winter \& Monsoon

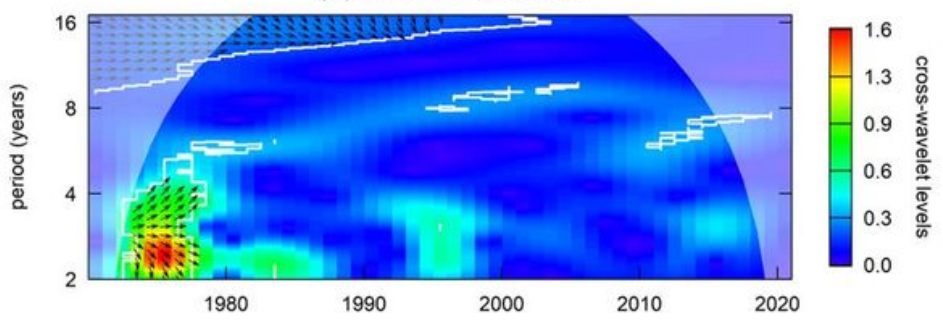

(D) Post-Monsoon \& Monsoon

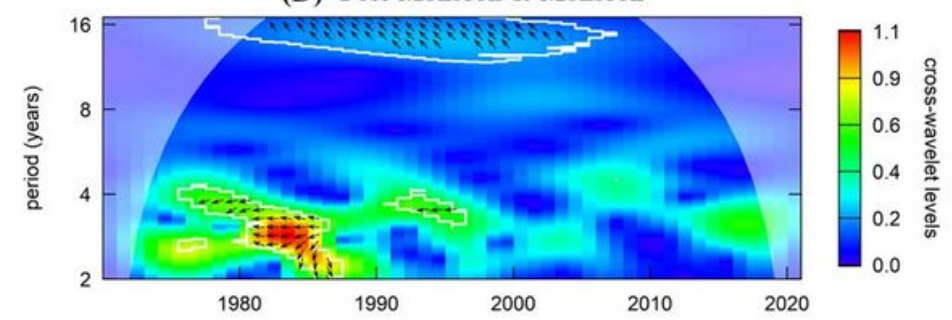

(F) Pre-Monsoon \& Post-Monsoon

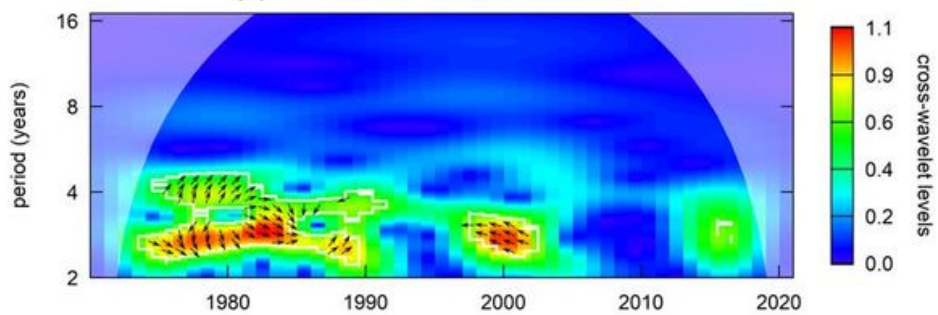

Figure 7

Spatial plot showing the regionalization (Clusters) of seasonal precipitation in the 4 IMD seasons over the Mahi River basin, India

\section{Supplementary Files}

This is a list of supplementary files associated with this preprint. Click to download.

- GraphicalAbstract.docx 